\title{
ИМИДЖ ПОЛИТИЧЕСКОГО ЛИДЕРА - БАЗОВЫЕ КАТЕГОРИИ
}

\begin{abstract}
Целью настоящей статьи является представление основных категорий, характеризующих феномен имиджа политического лидера, а также процесса его формирования в условиях современного конкурентного политического рынка. Автор обосновывает тезис, что миром правят образы людей, а политическое пространство формируют не партии, а имена лидеров, так как современная политика носит крайне персонифицированный характер. Для того, чтобы персонификация была успешной, необходимо уделять особое внимание „отгораживанию” кандидата от его конкурентов, акцентированию не только политических, но и сугубо личностных характеристик, наиболее выгодно отличающих его от других политиков. Автор считает, что политический лидер является одним из ведущих актеров политического процесса, а политическое лидерство выступает как институт взаимодействия между лидером и его последователями. Имидж лидера формируется и используется в качестве инструмента реализации роли лидера и функционирования института лидерства. Соответственно, при такой постановке вопроса на передний план выходят внешние характеристики политика. Это не всегда имеет прямое отношение к реальным способностям и возможностям политика выполнять свою конкретную роль во властных структурах. Однако именно это помогает ему войти в такие структуры то есть стать политиком. Автор анализирует имидж лидера также с философских позиций - как форму жизненного существования человека. Ореол необычного человека, исторической личности, который политик приобретает в качестве имиджа, включает через сопереживание, идентификацию и др. механизмы внутреннюю энергетику избирателей. Ее концентрация и позволяет политику в конечном счете подняться над текущей ситуацией. Одна из самых действенных маркетинговых стратегий для завоевания доверия избирателей, по мнению автора - показать, что лидер похож на избирателей, что у него одинаковые с ними заботы и проблемы, что он - „один из них”. На основании проведенного в статье сформулированы выводы о том, что, характер имиджа должен учитывать культурную специфику, уровень образования населения, экономическую ситуацию и ментальность народа, а также что наполнение имиджа обусловлено конкретным отрезком временем.
\end{abstract}

Ключевые слова: имидж, политический лидер, онтологический аспект имиджа, гносеологический аспект имиджа.

${ }^{1}$ Prof. dr hab. Aleksandr Gugnin, Politechnika Rzeszowska, Wydział Zarządzania, Katedra Marketingu, al. Powstańców Warszawy 8, 35-959 Rzeszów, autor korespondencyjny: guga@prz.edu.pl

${ }_{2}^{2}$ Dr Julia Lisnievska, Dnipropetrowski Regionalny Instytut Zarządzania Państwem, Katedra Prawa i Eurointegracji. 


\section{1. ВВЕДЕНИЕ}

В науке понятие политического образа появилось благодаря американскому ученому и публицисту У. Липпману еще в 1921году, когда он обратил внимание на факт, что общественное мнение о политиках часто бывает фрагментарным и деформированным.

Современные американские социологи, изучая общественное мнение электората, пришли к заключению, что избиратель принимает решение в первую очередь на основе оценки личности кандидата. Специалист в области политической рекламы Дж. Нейполитен искренне уверяет: „Политические позиции кандидата не столь важны, как то впечатление, которое он производит"з.

Английское слово image происходит от латинского imitati, что означает „подражать”. Популярный словарь английского языка переводит этот термин как „умелое подражание или представление внешней формы какого-нибудь объекта или личности”. Согласно польского словаря Э.Соболя это „образ, портрет определенного лица, созданный на основе его профессиональной деятельности и черт личности",

Российский ученый О.Феофанов настойчиво подчеркивал различие в значениях английского слова image и русского слова образ. Он считал,что имидж это такое отображение воспринимаемого явления, при котором ракурс восприятия умышленно смещается, акцентируется восприятие определенных сторон рассматриваемого явления 5 .

\section{2. ФИЛОСОФСКАЯ ИНТЕРПРЕТАЦИЯ ИМИДЖЕЛОГИИ}

В том контексте, в котором термин „имидж” употребляется в общественнополитической литературе, он обозначает более или менее иллюзорное отражения того или иного обьекта или личности. На пример, в настоящее время на Западе у Михаила Горбачева сохраняется устойчивый имидж радикального реформатора, в то время какв России его видят политиком-неудачником, способствовавшим развалу Советского Союза. Истина в оценке данного лидера находится посредине этих крайностей.

Мы же хотим лишь подчеркнуть, что имидж в гносеологическом концепте - это отражение, которое возникает и закрепляется в сознании самих воспринимающих. Извне, как удачно заметил выдающийся российский специалист в области теории политического маркетинга Дмитрий Ольшанский, „им может предлагаться только та или иная имиджевая модель. Как в природе нет живущих особой жизнью образов, так и в рекламе нет автономно функционирующих имиджей", . Мы считаем, что данный вопрос находится в плоскости онтологии политического имиджа.

Соотношение феноменов и понятий политического лидера, политического лидерства и имиджа лидера может быть осмыслено следующим образом: политический лидер является одним из ведущих актеров политического процесса;

\footnotetext{
${ }^{3}$ Д. Ольшанский, Политический PR, Изд. Питер, СПб 2003, с. 324.

${ }^{4}$ E. Sobol (red.), Stownik wyrazów obcych, PWN, Warszawa 1996, c. 462.

${ }^{5}$ А. Гугнин, Некоторые особенности развития рекламы в России, „Грани” 2005, №1(39), Днепропетровск, с. 78.

${ }^{6}$ Д. Ольшанский, op.cit., с. 287.
} 
политическое лидерство выступает как институт взаимодействия между лидером и его последователями. Имидж лидера формируется и используется в качестве инструмента реализации роли лидера и механизма функционирования института лидерства.

Полагаем, что природа имиджа двойственна, включает постоянные и переменные компоненты. „Инвариантный аспект имиджа, - пишет Ольга Мякотина, - определен его атрибутивностью - тем, что способность к самоимиджированию является неизменным компонентом лидерского арсенала. Переменный аспект имиджа обусловлен использованием его в качестве механизма реализации лидерских функций. При этом имидж, являясь неотъемлемым вневременным атрибутом лидерства, подвержен изменениям и в качестве механизма реализации лидерства в ходе социокультурных трансформаций общества",

Авторы, занимающиеся данной проблематикой, приводят разные определения ключевого понятия. В.Шепель, автор книги „Имиджелогия»”относит имидж к визуальной привлекательности личности и пишет, что „счастлив тот, кто обладает от Бога привлекательным имиджем. Но, как правило, многие обретают симпатии людей благодаря искусству самопрезентации. Без него не достичь крупных успехов в любой деятельности, не постичь радости человеческого внимания" то же говорит и О.Феофанов, называющий имиджем „набор определенных качеств, которые люди ассоциируют с определенной индивидуальностью”. Несколько иную позицию занимает Г. Гуревич, считающий, что понятие „имидж связано как с внешним обликом, так и внутренним содержанием человека, его психологическим типом, черты которого отвечают запросам времени и общества"10.

Теперь об определении имиджа политического лидера. О.Гордеева называет имиджем „определенные черты, качества лидера, взятые в единстве политических, мировоззренческих, биографических, внешних качеств, резонирующих в предпочтениях электората"11. Имидж, как считает В.Музыкант, это „усеченное представление о лидере, отдельная грань, намеренно демонстрируямая последователям. Имидж может быть либо ложным (в этом случае из лидера пытаются сделать того, кем он в действительности не является), либо правдивым тогда лидер обязан обладать приписываемыми качествами”, . „Имидж, - как считает М.Кошелюк, - есть отражение политиком избирателя. Политик - это зеркало, но зеркало „продвинутое”. В этом зеркале избиратель находит то, что скрыто в глубине его самого" ${ }^{\text {. }}$.

Таким образом, политтехнологи настаивают на важности имиджа, рациональной составляющей значимости политико-идеологического и программного компонента имиджа. А в целом, завершая обзор определений, можно сделать вывод, что в коммуникативном пространстве циркулируют различные образы:

${ }^{7}$ О. Мякотина, Имидж политического лидера. Диссертация... кандидата политических наук: 23.00.02, Москва 2008, с. 6.

${ }^{8}$ В. Шепель, Имиджелогия, Изд. Феникс, Москва 2005, с. 137.

${ }_{9}^{9}$ О. Феофанов, Реклама: Новые технологии в России, Изд. Питер, СПб 2000, с. 41.

${ }^{10}$ Г. Гуревич, Приключения имиджа, Изд. Искусство, Москва 1984, с. 31.

${ }^{11}$ О. Мякотина, op. cit. с. 6.

${ }^{12}$ Ibidem.

${ }^{13}$ М. Кошелюк, Технологии политических выборов. Изд. Питер, СПб 2004, с. 123. 
1) образ, каким его представляет субъект - политический лидер, кандидат,

2) образ, целенаправленно создаваемый,

3) образ, фактически складывающийся в сознании аудитории, последователей лидера.

Все три образа, отмечает О.Мякотина, существуют не обособленно друг от друга, между ними имеется сложная система связей, они способны друг на друга влиять. Исходя из этого положения, структура имиджа может быть представлена как некий набор ролей, объединенных внутренней логикой. Именно поэтому, утверждает Е.Новикова, полноценный имидж может быть сформирован только через совокупность образов - прототипов, конкретизированных в большей или меньшей степени ${ }^{14}$. Первоначальной задачей создания имиджа, пишет российская ученая, является определение индивидуальной „исторической” роли, определение прототипа, в канву которого будет вплетен имидж кандидата. Мы абсолютно согласны с данной точкой зрения. В одной из работ, посвященной имиджелогии, мы обосновали соответствующую концепцию ${ }^{15}$. „Прототип всегда лежит в основе имиджа, и только крупные исторические фигуры способны задавать новые прототипы" . Имидж любого политика, развивает свою мысль Е. Новикова, восходит к архетипу Героя-лидера. Проекция данного архетипа на конкретную личность придает ей тот ореол, который поднимает личность над ситуацией и над самой собой. Доказательством способности политика в качестве героя побеждать врага могут быть только конкретные факты его биографии. Поэтому легенда своеобразная биография, где ярко выделены характеристики и события, придающие имиджу политика героические черты. Таким образом, заключает автор, имидж существует как в зазоре между конкретной индивидуальностью и абстрактным образом - архетипом. Функция упоминавшихся российской ученой прототипов заключается в опосредовании этой связи. Абстрактный архетип существует в виде определенного набора культурных типов, вариантов. Эти типы фиксируются через сказочные и литературные персонажи, исторические личности, т.е. через некий набор имиджей конкретных в прошлом личностей, уже прошедших тот самый путь восхождения над ситуацией. Актуализация архетипа может осуществляться не только на личностном уровне, но и через типовые поступки в сходных ситуациях, аналогичный способ решения проблем, параллели на уровне эпох и стран. Через подобные прямые и косвенные параллели устанавливается канал связи с архетипем, который крайне важен. Именно через него, рассуждает Е. Новикова, происходит „вброс в актуальную ситуацию энергетики, которой, в принципе, не может обладать ни один обычный человек. Ореол героя, необычного человека, исторической личности, который политик приобретает в результате, актуализирует через сопереживание, идентификацию и другие подобные механизмы внутреннюю

\footnotetext{
${ }^{14}$ Е. Новикова, Технологии и механизмы формирования имиджса политического лидера, Известия высших учебных заведений, Общественные науки, Поволжский регион 2009, №2, с. 4.

${ }^{15}$ A. Gugnin, G. Ostasz, J. Lisniewskaja, Ontologiczne podstawy kreowania wizerunku liderów politycznych (aspekt historyczny), Półrocznik Saeculum Christianum, Rok XIX, 2012, №2, c. 209.

${ }^{16}$ Е. Новикова, оp.cit., с. 16
} 
энергетику избирателей. Ее концентрация и позволяет политику в конечном счете подняться над текущей ситуацией"17.

Таким образом, в структуру имиджа входят как реальные черты политика, так и черты ему приписываемые. (Путин, например, не может быть эффективным президентом, и результативным игроком в хоккей, как представляют его нынешние имиджмейкеры). Но сила имиджа лидера во многом определяется именно способностью вызывать такое „приписывание”. На языке политической психологии подобный процесс обозначают термином „проекция”. Проецируемое содержание обладает, с одной стороны, высоким уровнем личностной значимости, а сдругой не поддается сознательному контролю. Поэтому и верит российский обыватель в „универсальность” своего нынешнего лидера.

\section{3. ТИПЫ ПОЛИТИЧЕСКИХ ИМИДЖЕЙ}

Коллективная проекция архетипа героя на конкретную личность является не только механизмом формирования имиджа, но также имеханизмом коллективного интуитивного постижения ситуации и, далее, еe опосредованного, через делегированные политику полномочия, изменения. Формирование имиджей политиков является почти единственной доступной для массового субъекта формой коллективного осознания общественно-политической ситуации. Это коллективное творчество носит изначально образный, интуитивный и мифологический характер. Оно не может быть оформлено в виде парадигм, схем и понятий.

В связи с вышеизложенным Д.Ольшанский замечает, что создание имиджа напоминает иконопись. „Однако это особого рода иконы, строящиеся не на основе духовного образа Бога, а на фотографии живого политика. Икона - это только предполагаемый образ политического лидера. Очевидно, что в нем будет отражена специфика среды, для которой он будет создаваться. Икона - это уже образ, хотя образ, возникающий у смотрящего на нее человека - это уже далеко не икона. Условно можно говорить об образе первого порядка, который творит имиджмейкер, используя вместо доски и красок живого политика, расцвечивая его путем усиления одних и ослабления других его качеств, и образе второго порядка, возникающим у аудитории. Все различия в употреблении понятия имидж сводятся к тому, что считать имиджем - саму рукотворную икону, в которую превращает политика имиджмейкер, или тот внутренний образ, который возникает у верящих в него сторонников. Поэтому в тактическом смысле можно трактовать имидж как современную икону, а имиджмейкинг - как иконопись. Однако в стратегическом плане с учетом не только создания имиджа, но и его распространения и укоренения в массовом сознании имиджи - это те образы, которые возникают в психике людей под влиянием восприятия политических икон" 18 .

Обобщая вышеизложенное, можно выделить уровни структуры еще не созданного, а планируемого образа лидера. И речь будет идти о четырех его компонентах.

Первый компонент, как справедливо считает Д. Ольшанский, - это основа, база, некоторый „исходный материал” (политик, партия или организация), предварительно обработанный с целью минимизации негативных и максимизации

\footnotetext{
${ }^{17}$ Е. Новикова, op.cit., с.11.

${ }^{18}$ Д. Ольшанский, op.cit., с. 288.
} 
его позитивных черт в соответствии с основными параметрами оптимальной модели имиджа лидера. Например, новоизбранный президент Украины Петр Порошенко должен предстать решительным, справедливым и успешным лидером.

Второй компонент - это сама избранная модель имиджа, наложенная на предварительно подготовленный исходный материал. Моделью имиджа для специлиста может быть образ короля Испании Хуана Карлоса в начальный период его правления.

Третий компонент - неизбежные искажения, вносимые каналами трансляции имиджа (прежде всего средствами массовой информации) и способами его массового тиражирования. Наверняка в СМИ Украины новый президент будет представлен иначе, чем в информационных средствах России.

Четвертый компонент - результат активной собственной психической работы аудитории или отдельного субъекта восприятия по реконструкции итогового целостного имиджа в своем сознании на основе навязываемой извне модели, но с учетом собственных представлений о лидере. Самое важное - как будут оценивать имидж президента граждане его страны.

Подытоживая, следует констатировать, что имидж рассматривается как результат обработки сложного объекта не только социологами, психологами, маркетологами, политическими технологами, но и массовым сознанием обывателя актуального и будущего избирателя. При этом происходит, по словам Д. Ольшанского определенная кристаллизация отдельных черт и характеристик. Практически каждый объект нашего внимания из окружающего мира обладает своей имиджевой структурой ${ }^{19}$. Это может быть политик, выдающийся спортсмен или целое государство.

Однако имиджевая структура - только предпосылка для возникновения имиджа. Одни реальные характеристики входят в имидж и потому воспринимаются, тогда как другие не входят и могут не восприниматься. Несущественные характеристики при этом уходят на задний план. Например, травма руки (беспалость) Б.Ельцина никак не работала на его общий имидж. Поэтому она практически никем не воспринималась, также, как легкое прихрамывание Н. Саркози.

Имиджевые характеристики в политическом маркетинге делятся на психофизиологические (такие как активность, агрессивность, сила или мощь, а также противоположные им), личностно-коммуникативные (на практике связанные с каналом передачи информации, такие как фото- или телегеничность, тембр голоса), социальные (моделирующие человеческие качества, воспринимающиеся людьми как позитивные - доброта, отзывчивость, эмпатия), мифо-символические (подводящие лидера к имеющимся у граждан стереотипным представлениям) и профессионально-политические (отражающие требования и ожидания массовой аудитории к внешним и внутренним представлениям о данной профессии). Следует также отметить, что в практике моделирования имиджа лидера выделяются также контентные характеристики, зависящие от имиджа оппонента политика. Так, имидж В.Януковича в свое время строился как имидж сильного президента, приходящего на смену слабому В.Ющенку.

Однако все моделируемые характеристики имиджа должны, как считает Д.Ольшанский, идти в резонанс с системой представлений, существующих в

${ }^{19}$ Ibidem, c. 290. 
сознании среднего гражданина, на психику и интеллект которого планируется осуществлять воздействие. Основная задача специалистов, помимо создания модели, ее конструирования (пока еще не создания) имиджа это поиск возможностей технической реализации таких характеристик (см. табл.1).

\begin{tabular}{|c|c|c|c|}
\hline Тип & $\begin{array}{l}\text { С чем } \\
\text { резонирует }\end{array}$ & $\begin{array}{l}\text { Пример } \\
\text { характеристик }\end{array}$ & $\begin{array}{l}\text { Пример } \\
\text { реализации }\end{array}$ \\
\hline Биологический & $\begin{array}{l}\text { С примитивными } \\
\text { реакциями живот- } \\
\text { ного происхожде- } \\
\text { ния }\end{array}$ & $\begin{array}{l}\text { Сильный, } \\
\text { агрессивный }\end{array}$ & $\begin{array}{l}\text { Командирский голос, } \\
\text { уверенная речь, } \\
\text { режущий взмах руки и } \\
\text { т.п. }\end{array}$ \\
\hline Коммуникативный & $\begin{array}{l}\text { С особенностями } \\
\text { канала коммуни- } \\
\text { кации }\end{array}$ & Телегеничный & $\begin{array}{l}\text { Приятная улыбка, } \\
\text { умение рассмешить и } \\
\text { т.п. }\end{array}$ \\
\hline Социальный & $\begin{array}{l}\text { C семейными } \\
\text { представленями }\end{array}$ & $\begin{array}{l}\text { Доброта и вни- } \\
\text { мание к другим }\end{array}$ & \begin{tabular}{l}
\multicolumn{1}{c}{ Открытость, } \\
встречи с лю-дьми, \\
внимательное вслу- \\
шивание в чужую речь \\
и т.п.
\end{tabular} \\
\hline Мифологический & $\begin{array}{l}\text { Со стереотипными } \\
\text { представлениями } \\
\text { достаточно давнего } \\
\text { характера }\end{array}$ & „Рыцарь” & $\begin{array}{l}\text { Расправляется } \\
\text { „врагами” }\end{array}$ \\
\hline Профессиональный & $\begin{array}{l}\text { С представлениями } \\
\text { аудитории о } \\
\text { профессии }\end{array}$ & $\begin{array}{l}\text { Компетентност } \\
\text { ь, успех на преды- } \\
\text { дущем поприще }\end{array}$ & $\begin{array}{lr}\text { Умеет } & \text { говорить, } \\
\text { отвечать } & \text { на } \\
\text { вопожносы }\end{array}$ \\
\hline Контекстный & $\begin{array}{l}\text { С характеристи- } \\
\text { ками оппонента }\end{array}$ & $\begin{array}{l}\text { „Сильный” на } \\
\text { фоне „слабого” }\end{array}$ & $\begin{array}{l}\text { Отсутствие } \\
\text { компромата }\end{array}$ \\
\hline
\end{tabular}

Табл.1. Основные модели характеристик имиджа.

Таблица приведена по книге: Почепцов Г.Г., Паблик рилейшнз для профессионалов, Изд. Рефл-бук, Москва, Изд. Вакслер, Киев 2001, с.175.

Если подходить к имиджу лидера с философских позиций, то его следует рассматривать как форму жизненного существования человека. Поэтому имидж, пишет В.Шепель, не может быть только лишь „мертвым снимком”, в нем отражается состояние здоровья личности, ее душевность и духовность, ее ощущение конкретной жизненной ситуации ${ }^{20}$.

Обобщая приведенные объяснения смысла категории „имидж”, можно выделить три толкования персонального имиджа, каковым и является образ политического лидера:

1) американская версия, когда имидж рассматривается как средство достижения личностью целей;

2) европейская версия, когда имидж рассматривается как способ привлечения личностью внимания к себе;

3) русская версия, когда имидж рассматривается как условие самопрезентации достоинств личности.

${ }^{20}$ В. Шепель, Профессия имиджмейкер, Изд. Феникс, Ростов-на-Дону 2008, с. 137. 
Первые две версии имеют явно утилитарное значение. В русской версии, считает В.Шепель (ее автор) имидж рассматривается как „коммуникативная конструкция, обладающая особым эффектом коммуникативного (информационного) воздействия. При этом акцент делается на использования имиджа как подъемной силы для выведения наружу того лучшего, что имеет субъект, который позиционирует имидж"21.

Здесь можно позволить себе не согласиться с мнением российского ученого, хотя бы по той причине, что европейское видение коммуникативного смысла воздействия образа лидера на политическую действительность еще в 2004 году подробно представила польская исследовательница и политический консультант Мажена Чихош в книге „(Само)презентация имиджа политика”. Сущность этого взгляда состоит в маркетинговом рассмотрении, означающем, что имидж трактуется:

- во-первых, как политический продукт, представленный на рынке покупателям,

- $\quad$ во-вторых, как политический ресурс, т.е. то, чем располагает группа и что может превратиться в капитал, если в этом возникнет потребность,

- в-третьих, как капитал, т.е. такой тип ресурса, который при соответствующем использовании на рынке приносит прибыль 22 .

Однако не будем оспаривать первенство - не такое уж большое это научное открытие. Важно другое - что и российский, и европейский концепты имиджа, говоря философским языком, предполагают также его эвристическую функцию. (Например, распространенный на Западе имиджевый снимок Путина в военной шапке вполне вписался в его новый облик ,завоевателя Крыма”).

\section{4. ЗАКЛЮЧЕНИЕ}

Иными словами, проецирование „удачного” имиджа политического лидера главным образом зависит от следующих условий: от знания и понимания настроений, требований и установок своих настоящих и будущих последователей и умения показать, что данный политик - именно тот, кто полностью отвечает потребностям аудитории. Одна из самых действенных маркетинговых стратегий для завоевания доверия избирателей - показать, что лидер похож на них, что у него одинаковые с ними заботы и проблемы, что он - „один из них”. Чрезмерная оригинальность в сфере политики при формулировании программ, выборе технологий построения имиджа политического лидера недопустима, так как она оттолкнет от лидера большую часть граждан. Политические реалии современного общества таковы, что рядовой избиратель не имеет возможности личного контакта с политиком, тем более с политическим лидером. Он воспринимает политика таким, каким его представляют обществу СМИ, поэтому они играют достаточно важную роль в формировании имиджа.

И последний вывод. Имидж можно назвать также стратегическим образом. Он должен соответствовать некоторым обязательным особенностям. Во-первых, характер имиджа зависит, а точнее говоря, должен учитывать культурную

\footnotetext{
${ }^{21}$ Ibidem, 137.

${ }^{22}$ Cichosz M., Autokreacja wizerunku polityka na przykładzie wyborów prezydenckich w III RP,. Wyd. Adam Marszałek, Toruń 2004, c. 61.
} 
специфику, уровень образования населения, экономическую ситуацию и ментальность народа. Прическу и френч Ким Чен Ына наверняка бы не восприняли жители Южной Кореи, а кубинцы никогда не признали бы своим лидером олигарха. Во-вторых, имидж обусловлен и временем. Использование успешного в предыдущие годы имиджа не гарантирует удачи в последующих кампаниях, так как потребности избирателей меняются, как меняется обстановка в стране и мире. Другие времена требуют других героев.

\section{ЛИТЕРАТУРА}

[1] Ольшанский Д., Политический PR, Изд. Питер, СПб 2003.

[2] Нейполитен Дж., Электоральная игра, Изд. Никколо-М, Москва 2003.

[3] Sobol E. (red.), Stownik wyrazów obcych, PWN, Warszawa 1996.

[4] Гугнин А., Некоторые особенности развития рекламы в России, „Грани” 2005, №1(39), Днепропетровск.

[5] Мякотина О., Имидж политического лидера. Диссертация... кандидата политических наук: 23.00.02, Москва 2008.

[6] Шепель В., Имиджелогия, Изд. Феникс, Москва 2005.

[7] Феофанов О., Реклама: Новые технологии в России, Изд. Питер, СПб 2000.

[8] Гуревич Г., Приключения имиджа, Изд. Искусство, Москва 1984.

[9] Кошелюк М., Технологии политических выборов. Изд. Питер, СПб 2004.

[10] Новикова Е., Технологии u механизмы формирования имиджа политического лидера, Известия высших учебных заведений, Общественные науки, Поволжский регион 2009, №2.

[11] Gugnin A., Ostasz G., Lisniewskaja J., Ontologiczne podstawy kreowania wizerunku liderów politycznych (aspekt historyczny), Półrocznik Saeculum Christianum, Rok XIX, 2012, №2.

[12] Шепель В., Профессия имиджмейкер, Изд. Феникс, Ростов-на-Дону 2008.

[13] Cichosz M., Autokreacja wizerunku polityka na przyktadzie wyborów prezydenckich

w III RP,. Wyd. Adam Marszałek, Toruń 2004.

\section{WIZERUNEK PRZYWÓDCY POLITYCZNEGO: PODSTAWOWE KATEGORIE}

Celem niniejszego artykułu jest przedstawienie bazowych kategorii, które charakteryzują zjawisko wizerunku lidera politycznego, jak i proces jego kreowania w dzisiejszym konkurencyjnym rynku politycznym. Autor uzasadnia tezę, że świat jest rządzony przez obrazy ludzi, a przestrzeń polityczna kształtowana jest nie przez partie polityczne, lecz przez nazwiska przywódców, ponieważ współczesna polityka ma charakter krańcowo personifikowany. Aby personifikacja była skuteczna, należy zwrócić szczególną uwagę na "odseparowanie" kandydata od jego konkurentów, akcentując nie tylko jego cechy polityczne, ale także całkiem osobowościowe, które w sposób najbardziej korzystny odróżniają go od innych polityków. Autor uważa, że przywódca polityczny jest jednym z czołowych aktorów procesu politycznego, a polityczne przywództwo występuję jako instytucja realizująca interakcję między przywódcą i jego zwolennikami. Wizerunek lidera jest kształtowany i stosowany jako narzędzie do realizacji roli lidera i funkcjonowania instytucji przywództwa. Jest oczywiste, że $\mathrm{z}$ tego punktu widzenia na pierwszy plan wychodzą cechy zewnętrzne polityka. Nie zawsze jest to bezpośrednio związane $\mathrm{z}$ 
rzeczywistymi umiejętnościami i zdolnością polityka do pełnienia konkretnej roli w strukturach władzy. Jednak, właśnie to pomaga mu dostać się do takich struktur - to jest zostać politykiem. Autor analizuje image lidera także z filozoficznego punktu widzenia, jako formę życia ludzkiego. Aureola niezwykłego człowieka, historycznej osobowości, którą polityk nabywa wraz z wizerunkiem politycznym, uruchamia przez empatię, identyfikację $\mathrm{i}$ in. mechanizmy wewnętrznej energetyki wyborców. Jej koncentracja i pozwala politykowi w ostateczności wzrosnąc powyżej obecnej sytuacji. Jedna z najbardziej skutecznych strategii marketingowych stosowanych w celu wzbudzenia zaufania wyborców, według autora, to pokazanie, że lider jest podobny do wyborców, że maz nimi te same obawy i problemy, że - "jest jednym z nich". Na podstawie wniosków zawartych w tym artykule, autor wywodzi charakterystyczne cechy wizerunku przywódcy politycznego: wizerunek powinien uwzględniać specyfikę kulturową, poziom edukacji społeczeństwa, sytuację gospodarczą i mentalność narodową, a jego wewnętrzne wypełnienie ma być odpowiednie do realiów konkretnego okresu czasu.

Słowa kluczowe: wizerunek, przywódca polityczny, ontologiczny aspekt wizerunku, epistemologiczny aspekt image.

\section{IMAGE POLITICAL LEADER: BASIC CATEGORIES}

The purpose of this article is to introduce the main categories that characterize the phenomenon of the image of a political leader, as well as the process of its formation in today's competitive political market. The author substantiates the thesis that the world is ruled by images people and the political parties do not form a space, and the names of the leaders, as modern politics is extremely personified. To personification was successful, you need to pay special attention -"isolation" candidate from its competitors, accentuating not only political, but purely personal characteristics that most distinguishes it from other politicians. The author believes that a political leader is one of the leading actors of the political process, and political leadership institute acts as the interaction between the leader and his followers. Image of a leader is formed and used as a tool for the implementation of a leadership role and functioning of the Leadership Institute. Accordingly, when the question is posed to the fore the external characteristics of the policy. This is not always directly related to the real abilities and capabilities to carry out its policy of a specific role in the government. However, it is helping him get into such structures - that is to become a politician. The author analyzes the image of the leader as a philosophical standpoint - as a form of life of human existence. Halo unusual man, a historical person who acquires as a politician's image, including through empathy, identification, and other mechanisms of internal power of voters. Its concentration and allows policy ultimately rise above the current situation. One of the most effective marketing strategies to win the trust of voters, according to the author - to show that the leader is similar to the voters that he has with them the same concerns and problems that he - "one of them". Based on the conclusions stated in the article that the character's image should be culturally sensitive, educated population, economic situation and mentality of the people, and that the image content due to a particular slot.

Keywords: image, the political leader, the ontological aspect of the image, the epistemological aspect of image.

DOI:10.7862/rz.2014.hss.20

Przesłano do redakcji: maj 2014

Przyjęto do druku: lipiec 2014 